DR MANUEL FERREIRA-MAGALHÃES (Orcid ID : 0000-0001-9477-8822)

DR RITA AMARAL (Orcid ID : 0000-0002-0233-830X)

Article type : Original

\title{
Cost of asthma in children: a nationwide, population-based, cost-of- illness study
}

Manuel José Ferreira de Magalhães ${ }^{1-4 ;}$; Rita da Silva Amaral2; Ana Margarida Pereira ${ }^{2,5}$; Ana Isabel Alves de Sá e Sousa Santos²; Maria Inês Águeda de Azevedo1,3; Luís Filipe Ribeiro de Azevedo2,4; João Almeida Lopes Fonseca ${ }^{2,4,5}$

${ }^{1}$ Department of Pediatrics, Centro Hospitalar de S. João, Porto, Portugal; ${ }^{2}$ CINTESIS - Center for Health Technologies and Information Systems Research - Faculty of Medicine, University of Porto, Porto, Portugal; ${ }^{3}$ Department of Pediatrics- Faculty of Medicine, University of Porto, Porto, Portugal; ${ }^{4}$ MEDCIDS Department of Community Medicine, Health Information and Decision - Faculty of Medicine, University of Porto, Porto, Portugal; ${ }^{5}$ Allergy Unit, CUF Institute \& Hospital, Porto, Portugal

Running Title: Cost of asthma in children

\section{Correspondence:}

João Almeida Fonseca, MD, PhD

CINTESIS - Center for Health Technology and Services Research

Centro de Investigação Médica, Faculdade de Medicina da Universidade do Porto

Edifício Nascente, Piso 2

Rua Dr. Plácido da Costa, s/n

4200-450 Porto, Portugal

Tel: +351 914767661 ; Fax: +351225 513623 ; E-mail: jfonseca@med.up.pt

This article has been accepted for publication and undergone full peer review but has not been through the copyediting, typesetting, pagination and proofreading process, which may lead to differences between this version and the Version of Record. Please cite this article as doi: $10.1111 /$ pai. 12772

This article is protected by copyright. All rights reserved. 
Ferreira-Magalhães M, Amaral R, Pereira AM, Sá-Sousa A, Azevedo I, Azevedo, LF, Fonseca J. Pediatr Allergy Immunol

\begin{abstract}
Background: Childhood asthma is very prevalent and costs can be high, especially in severe disease. This study aimed to estimate the cost of asthma in Portuguese children and the variations by level of asthma control.
\end{abstract}

Methods: A nationwide, population- and prevalence-based cost-of-illness study with a societal perspective was conducted. We measured direct and indirect costs using a bottom-up approach and a human capital method, respectively, for 208 children ( $<18$ years), from two national repositories. Generalised linear modelling for analysis of asthma costs' determinants and sensitivity analysis to assess uncertainty were performed.

Results: The mean annualised asthma cost per child was €929.35 (95\%CI, 809.65-1,061.11): $€ 698.65$ (95\%CI, 600.88-798.27) for direct costs, and €230.70 (95\%CI, 197.36-263.81) for indirect costs. Extrapolations for the Portuguese children amounted to €161,410,007.61 (95\%CI, 140,620,769.55-184,293,968.55) for total costs. Direct costs represent $75.2 \%$ with the costliest domain (51.1\% of total costs) being the healthcare service use: $20.7 \%$ for scheduled medical visits and $30.4 \%$ for acute asthma care - non-scheduled medical visits $(7.9 \%$, $€ 12,766,203.20)$, emergency department visits $(11.7 \%, € 18,932,464.80)$ and hospitalisations $(10.8 \%, € 17,406,946.00)$.

Children with partly controlled and uncontrolled asthma had higher mean costs per year (adjusted coefficients: 1.46 [95\%CI, 1.12-1.90] and 2.25 [95\%CI, 1.56-3.24], respectively).

Conclusions: Costs of childhood asthma are high $(0.9 \%$ of the healthcare expenditures in Portugal). Direct costs represented 3/4 of total costs, mainly related to the use of healthcare services for acute asthma care. Policies and interventions to improve asthma control and reduce acute use of healthcare services have the potential to reduce asthma costs.

Keywords: burden, economics, health services research, pediatrics, pulmonary medicine

\title{
Requests for offprints:
}

João Almeida Fonseca, MD, PhD

CINTESIS - Center for Health Technology and Services Research

Centro de Investigação Médica, Faculdade de Medicina da Universidade do Porto

Edifício Nascente, Piso 2

This article is protected by copyright. All rights reserved. 
Rua Dr. Plácido da Costa, s/n

4200-450 Porto, Portugal

Tel: +351914 767661 ; Fax: +351225 513623 ; jfonseca@med.up.pt

\section{Introduction}

Health economic studies are important to support decision-makers in defining health priorities (1-3). In light of the increasing healthcare costs and the consequent threat to the sustainability of healthcare systems, focus should be put in assessing the impact of chronic diseases, aiming to reduce their burden (4).

As one of the most common chronic diseases in childhood, asthma should have reliable economic data available. In childhood asthma, important direct costs (diagnostic tests, medications, medical visits, hospitalisations or emergency admissions) and indirect costs (mainly caregivers' loss of work days and transportation to healthcare services) are relevant and can be high, especially in severe disease (5). In 2002, Druss et al have quoted asthma as the $13^{\text {th }}$ most expensive medical condition in the USA (6). In 2011, Barnett and Nurmagambetov used a regression-based method to estimate $\$ 56$ billions of incremental costs in all-age asthmatic USA population, with a mean value of $\$ 3,259$ per person/year (7). In the same year, Bravo et al estimated the cost of asthma in children younger than 15 years old, in Spain, to be $€ 532$ million, (€1,149 person/year) (5). In the same study, the costs within each category of asthma severity ranged from $€ 403$ for the mildest to $€ 5,930$ for the most severe (costs person/year). Even though other asthma economic studies have been conducted, there are few population based and comprehensive pediatric cost-of-illness studies (8).

This study aimed to estimate the cost of childhood asthma in Portugal. Secondary aims were: 1) to describe direct and indirect costs, 2) to determine factors associated with costs, and 3) to assess costs according to the level of asthma control.

\section{Methods}

\section{Study design and setting}

The Cost of Childhood Asthma in Portugal (CASCA project) was a Portuguese, nationwide, population- and prevalence-based, cost-of-illness study with a societal perspective. This project was reviewed and approved by the Ethics Committee of Centro Hospitalar de São João, Porto, Portugal. Informed consent was obtained from parent(s) or legal guardian(s).

\section{Participants and data collection}

Data from participants of two studies (INAsma and CED2013) was analysed. INAsma was a nationwide survey, from the general population, applied by telephone interview to individuals living in Portugal, in 2010 (9,10). CED2013 was a population-based survey applied to children

This article is protected by copyright. All rights reserved. 
attending primary public schools in a Portuguese city (Guimarães), in 2013. Questionnaires were similar in the both studies, however, data on diagnostic tests use were only available in the CED2013 study (questions used are presented in Table S1). When the selected participant was younger than 15 years old, the respondent was the usual and most knowledgeable caregiver. For the CASCA project we included 208 children with current asthma (CA): 98 (0- to 17-years old) from the INAsma Study and 110 (5- to 12-years old) from the CED2013 Study (Fig. S1). Participants and data collection are further described in supplementary material.

Data collection of prices of healthcare services, diagnostic tests, medication, holding chambers, absenteeism, transportation and subsidies were performed in different sources and databases as described below and in supplementary material.

\section{Cost estimation methods}

Direct healthcare costs of childhood asthma were estimated using a bottom-up approach (person-based). The cost domains included in direct costs were: 1) healthcare services (scheduled medical visits, non-scheduled medical visits, emergency department visits and hospitalisations); 2) diagnostic tests (blood workouts, skin prick tests, spirometries and chest xray); and 3) treatment (asthma-specific medication, other asthma-related medication and medical devices). Databases and reports from the Portuguese Central Administration of Health System (Administração Central dos Serviços de Saúde) (11), the Ministry of Health (12) and the National Authority of Medicines and Health Products (Infarmed) (13) were used to achieve unitary costs (mean prices per medication dose are presented in Table S2). A mean usage scenario for each medication was achieved by consensus, in accordance with international guidelines (14), in case of parent/self-reported use of the corresponding medication (used scenarios are presented in Table S3).

Indirect costs of childhood asthma were estimated using the human capital method. The cost domains included in indirect costs were: 1) absenteeism; 2) transportation and 3) subsidies because of asthma. Databases and reports from the National Statistics Institute (Instituto Nacional de Estatística) (15) and the Ministry of Social Security $(16,17)$ were used to achieve unitary costs.

Each cost item was calculated for each participant by multiplying the parent/self-reported amount of resources used by the unitary costs of the resources. The total cost was then calculated for each participant by adding direct and indirect costs. Mean cost per patient was achieved by the sum of the total cost of each participant, dividing for the total number of asthmatic children in our sample. Costs were indexed to 2010 Portuguese prices in euros. Cost estimation methods are further described in supplementary material.

This article is protected by copyright. All rights reserved. 


\section{Definitions}

CA was defined as children that 'ever had asthma' plus at least one of the following: wheezing, awakening with breathlessness or having an asthma attack in the previous 12 months, or taking asthma medication at the time of the interview. Asthma control was defined according to GINA (14), and categorised into 'controlled', 'partially controlled' and 'uncontrolled'. Definitions for other variables are described in supplementary material.

\section{Statistical analysis}

Statistical analysis was performed using SPSS version 23 (SPSS IBM, New York, NY, USA). General characteristics of the included participants were described using absolute and relative frequencies.

Cost variables were all annualised and presented as mean and standard deviation (SD) or 95\% confidence interval $(95 \% \mathrm{CI})$, calculated using bootstrap methods because of their skewed distributions $(18,19)$. For each cost item and domain, extrapolated estimates for the Portuguese population were calculated. Extrapolation estimates were based on a prevalence estimate of CA from the INAsma Study (8.4\% [95\%CI, 6.6-10.7]), corresponding to a total weighted population of 173,681 Portuguese children with CA (9). The factors associated with costs of childhood asthma and, specifically, differences in levels of asthma control, were assessed using mixed Poisson-gamma models. A p-value of $<0.05$ was considered statistically significant.

We additionally used decision analytic modelling to perform univariate and multivariate deterministic sensitivity analysis, in order to evaluate how the uncertainty would impact the estimates of national annualised costs of childhood asthma in Portugal. Univariate deterministic sensitivity analysis was performed with the $95 \%$ CI of the proportion estimates of occurrence of each item in Portuguese population. The multivariate deterministic sensitivity analysis was set with two case scenarios. The best-/worst-case scenario were set, respectively, with: the lower/upper limit of the 95\%CI of CA prevalence in Portuguese children; scenario of minimum/maximum use of asthma medications (Table S3); and the lower/upper limit of the 95\%CI for the proportion of occurrence of each item in Portuguese population.

\section{Results}

Characteristics of the children included in cost-of-illness analysis are summarised in Table S4. Estimates of mean annualised costs for each cost domain are presented in Table 1 (in Table S5 are presented the mean costs estimated for each of the two primary studies used in the analysis). The mean annualised total costs per child were €929.35 (95\%CI, 809.65-1,061.11), with €698.65 (95\%CI, 600.88-798.27) for direct costs, and €230.70 (95\%CI, 197.36-263.81) for indirect costs. The extrapolations for Portuguese children amount to absolute total costs of $€ 161,410,007.61$ (95\%CI, 140,620,769.55-184,293,968.55), with direct costs of $€ 121,341,498.02$ (95\%CI, 104,362,186.11-138,645,096.07) and indirect costs of $€ 40,068,509.59$ (95\%CI, 34,276,935.33-45,819,027.76).

This article is protected by copyright. All rights reserved. 
Direct costs represented $75 \%$ and indirect costs $25 \%$ of the total costs. The most expensive domain was healthcare services use (€82,519,684.10; $51 \%$ of total costs), specifically scheduled medical visits (€33,414,070.10; $21 \%$ of total costs) and medical visits related to acute asthma care $(€ 49,105,614.06 ; 30 \%$ of total costs): which encompassed non-scheduled medical visits $(€ 12,766,203.20)$, emergency department visits $(€ 18,932,464.80)$ and hospitalisations $(€ 17,406,946.00)$.

\section{Factors associated with costs of asthma}

We observed significant crude associations between total annualised costs of childhood asthma and nocturnal symptoms, asthma attacks and level of asthma control (Table 2). However, only asthma attacks and level of asthma control had significant and independent associations with total annualised costs of childhood asthma in the final multivariate model adjusted for age.

Children with asthma attacks in the previous 12 months had higher costs than those without asthma attacks (adjusted exponential model coefficients: 1.57 [95\%CI, 1.22-2.02]). Children with partly controlled asthma and uncontrolled asthma had higher mean costs per year with adjusted exponential model coefficients of 1.46 [95\%CI, 1.12-1.90] and 2.25 [95\%CI, 1.56-3.24], respectively. The mean annualised costs per asthmatic child were €747.63 in those with controlled asthma, $€ 1,120.50$ in partly controlled and $€ 1,758.44$ in uncontrolled $(p<0.001)$ (Fig. 1 ; Table S6). Total costs and direct costs, specifically healthcare services use by acute asthma care and diagnostic tests domains, were significantly higher in children with uncontrolled asthma (Fig. 2). Scheduled medical visits, treatment or indirect costs were not different between asthma control groups.

\section{Sensitivity analysis}

The univariate deterministic sensitivity analysis is presented in supplementary material (Table S7). The multivariate deterministic sensitivity analysis is presented in Table 3 . The mean cost estimates per child with asthma varied between $-35 \%$ and $+53 \%$ for total costs, between -36 and $+63 \%$ for direct costs, and between -30 and $+23 \%$ for indirect costs.

\section{Discussion}

We conducted a cost-of-illness analysis on Portuguese childhood asthma, with a prevalencebased, societal perspective, that allowed a broad economic analysis of the disease. We adopted a societal perspective, the most comprehensive approach, because it uses the direct and indirect costs for all members of the society (20). From a societal perspective, childhood asthma in Portugal costs over €150 million per year, corresponding to more than €900 per child with CA. Childhood asthma costs correspond to $0.91 \%$ of the Portuguese expenses in health in 2010. These expenditures are undertaken together by patients, by the Portuguese state and by health insurance companies, depending on the type of healthcare services used. Direct costs were 3/4 of the costs, with most being related to healthcare services use and especially to acute asthma care. The most important factors for higher costs were uncontrolled asthma (2.3-fold) and asthma attacks in the previous 12 months (1.6-fold).

This article is protected by copyright. All rights reserved. 


\section{Total, direct and indirect costs of childhood asthma}

The cost estimates for childhood asthma in Portugal were slightly lower than the Spanish estimates in 2008 ( $€ 1,149$ child/year) (5); however, in this Spanish study the proportion of healthcare services use, diagnostic tests use, medication use and absenteeism because of childhood asthma were based on expert opinions; this could have overestimated these Spanish cost estimates. Otherwise, USA estimates for 2008 prices of 5- to 17-years old asthmatics were lower than ours: $\$ 791$ child/year (direct costs, $\$ 401$ child/year; indirect costs, $\$ 390$ child/year) (21). In that study, the authors analysed data from the 1996 Medical Expenditure Panel Survey and the type of asthma-related expenditures used in direct costs were not clear. In Turkey, a study performed in 2006, in pediatric allergy and asthma referral centres, reported medical and non-medical costs of $\$ 1,597$ per child/year (medical, $\$ 775$; non-medical, $\$ 821$ ), however, no formal indirect costs were reported (22). The definition of medical costs was similar to our definition of direct costs, and the results were also similar (assuming an 1.23 exchange rate of dollar to euro, in 2006). Non-medical costs included transportation (not absenteeism), but were mainly driven by non-allergic household measures (\$710) like air filters, special vacuum cleaners or anti-allergic bed covers, that we did not assess in our study, as the current guidelines do not recommend them (14).

Previously published studies reported proportions of direct costs between 61-88\% (8). Healthcare services use in the context of asthma worsening (non-scheduled medical visits, emergency and hospitalisations) were, altogether, $30 \%$ of the total costs of childhood asthma in Portugal. Reducing acute asthma care costs should be one of the major targets for potential savings. Also, by reducing it, other domains (e. g., indirect costs) could also be lowered as poor controlled asthma is associated to higher unscheduled medical visits and higher costs of lost work $(10,23)$.

Indirect costs were one-fourth of the costs in childhood asthma. Other studies showed that indirect costs can be as high as 50\% (8). The lack of assessment of costs related to presenteeism and lower salaries in Portugal may justify our proportion of indirect costs. Nevertheless, more than 13 million euros were spent yearly with parental absenteeism because of childhood asthma. This value can represent a potential higher burden to society, as loss of parental work can further impact the overall economy.

\section{Determinants of cost variation in childhood asthma}

The most important determinants for higher costs were asthma attacks in the previous 12 months (1.6-fold) and having uncontrolled asthma (2.3-fold). Direct costs were significantly higher in children with uncontrolled asthma, specifically acute asthma care and diagnostic test use. Interestingly, there were no significant differences in costs of scheduled medical visits and treatment for controlled $v s$. uncontrolled children.

Considering a hypothetic scenario (data not shown) in which all Portuguese children with asthma were controlled, the savings would be more than $30,000,000 €$ per year $(20 \%$ reduction). As previously reported, children with not controlled asthma had significantly more unscheduled medical visits and hospitalisations $(10,24)$; knowing that uncontrolled asthma is, also, the major determinant for higher costs, effective policies should be directed to improve

This article is protected by copyright. All rights reserved. 
asthma control and reduce acute care medical visits. Other studies showed that asthma plans/interventions can reduce symptoms, reduce healthcare services use and be cost-effective $(25,26)$.

Future studies should be designed to have multinational cost-of-illness data, aiming to understand differences between asthma care and to compare outcomes. Quality-of-life assessment in childhood asthma should also be improved and be part of a burden of disease analysis.

\section{Strengths and limitations}

This was the first Portuguese nationwide, population-based study on costs of childhood asthma. The cost domains analysed allowed us to create a comprehensive picture of childhood asthma costs in Portugal, as did the prevalence-based analysis and societal perspective. We performed a univariate and multivariate deterministic sensitivity analysis, aiming to understand different variations according to uncertainty. Sensitivity analysis is crucial to highlight variability, to make comparisons with other data, and is recommended in economic studies $(27,28)$, but this was the first cost-of-illness study on childhood asthma to report a thorough sensitivity analysis for each cost domain.

There were some limitations regarding the data collection, participants and reported outcomes used for cost estimations. There are no validated questionnaires for cost-burden analysis in asthma (29), yet we used simple direct questions similar to other studies (8). Participants were derived from INAsma (national sample) and CED2013 (one city sample); school-age children may be overrepresented in our sample, nevertheless, this is the age group with the higher prevalence of asthma in our country (9). Also, differences in cost estimations between the two studies were only seen in the domain of 'Treatment' and total costs were not significantly different (Table S5). Data on diagnostic tests use were only available in the CED2013 study and then extrapolated for the entire sample. The assumptions made in the treatment domain may also have masked higher cost differences between asthma control groups. Specifically, medication costs were based on the reported medicines used in the previous year, but we were unable to assess the number of doses taken by each participant; we used a clinical consensus approach for the number of doses of controller and reliever medication, based on GINA guidelines and on conservative estimations of adherence. In transportation, we used an official Portuguese price by kilometre; however, we could not assess how many of the patients used public transports or ambulances. The absenteeism costs were not based on the reported income, but rather on a mean Portuguese daily income according to the parents' professional occupation, which could possibly underestimate the costs of absenteeism. Also, we could not assess parents' presenteeism because of child's asthma.

In conclusion, childhood asthma in Portugal costs $€ 161,410,007.61$ per year, corresponding to $€ 929.35$ per child with CA. The total cost estimate of childhood asthma corresponds to $0.91 \%$ of the Portuguese expenses in health in 2010. Direct costs were 3/4 of total costs, mainly related to acute asthma care (non-scheduled visits, emergency and hospitalisations). The most important factors determining higher costs were asthma attacks in the previous 12 months (1.6-fold) and uncontrolled asthma (2.3-fold). A better asthma control, with a consequent reduction in the acute use of healthcare services, should be the major target for potential savings in this disease.

This article is protected by copyright. All rights reserved. 


\section{Funding and acknowledgments}

CASCA Project was financed by a Calouste Gulbenkian Foundation competitive grant (P125964).

We thank the Sociedade Portuguesa de Alergologia e Imunologia Clínica; Sociedade Portuguesa de Pneumologia and Fundação Ciência e Tecnologia - Harvard Medical School Portugal (HMSPIDSIM/SIM/0018/2009) which supported the INAsma Study.

\section{References}

1. Williams I, McIver S, Moore D, et al. The use of economic evaluations in NHS decisionmaking: A review and empirical investigation. Health Technol Assess 2008: 12(7).

2. Larg A, Moss JR. Cost-of-illness studies: A guide to critical evaluation.

Pharmacoeconomics 2011: 29: 653-671.

3. Jo C. Cost-of-illness studies: concepts, scopes, and methods. Clin Mol Hepatol 2014: 20: 327-337.

4. Goodman CS. HTA 101: Introduction to Health Technology Assessment. Bethesda, MD: National Library of Medicine (US) 2014.

5. Blasco Bravo AJ, Pérez-Yarza EG, De Mercado PLY, et al. Coste del asma en pediatría en España: un modelo de evaluación de costes basado en la prevalencia. An Pediatr 2011: 74: 145153.

6. Druss BG, Marcus SC, Olfson M, et al. The most expensive medical conditions in America. Health Aff 2002: 21: 105-111.

7. Barnett SBL, Nurmagambetov TA. Costs of asthma in the United States: 2002-2007.J Allergy Clin Immunol 2011: 127: 145-152.

8. Bahadori K, Doyle-Waters MM, Marra C, et al. Economic burden of asthma: a systematic review. BMC Pulm Med 2009: 9: 1-16.

9. Ferreira-Magalhaes M, Sa-Sousa A, Morais-Almeida M, et al. Asthma-like symptoms, diagnostic tests, and asthma medication use in children and adolescents: a population-based nationwide survey. J Asthma 2016: 53: 269-276.

10. Ferreira-Magalhães M, Pereira AM, Sá-Sousa A, et al. Asthma control in children is associated with nasal symptoms, obesity, and health insurance: a nationwide survey. Pediatr Allergy Immunol 2015: 26: 466-473.

11. Serviço Nacional de Saúde - Relatório e Contas 2010. Administração Central dos Serviços de Saúde. Lisboa 2010.

12. Portaria n.ำ 132/2009 de 30 de Janeiro do Ministério da Saúde. Diário da República: 1ª série, n. ${ }^{-}$21. http://www.dre.pt (accessed 21 Jan 2015).

13. Infomed. http://app7.infarmed.pt/infomed (accessed 21 Jan 2015).

This article is protected by copyright. All rights reserved. 
14. Global Initiative for Asthma. Global Strategy for Asthma Management and Prevention, 2016. http://www.ginasthma.org (accessed 13 Sep 2016).

15. Classificação Portuguesa das Profissões 2010. Instituto Nacional de Estatística. Lisboa 2011.

16. Quadros de Pessoal 2010. Ministério da Solidariedade e Segurança Social. Lisboa 2012.

17. Portaria n. - 511/2009 de 14 de Maio do Ministério das Finaças e da Administração Pública e do Trabalho e da Solidariedade Social. Diário da República: 1aㅗ série, n. 993. http://www.dre.pt (accessed 21 Jan 2015).

18. Drummond MF, Sculper MJ, Torrance GW et al. Methods for the economic evaluation of health care programmes. 3rd ed. New York: Oxford University Press 2005

19. Briggs AH, O'Brien BJ, Blackhouse G. Thinking outside the box: recent advances in the analysis and presentation of uncertainty in cost-effectiveness studies. Annu Rev Public Health 2002: 23: 377-401.

20. Segel JE. Cost-of-Illness Studies - A Primer. RTI International, RTI-UNC Center of Excellence in Health Promotion Economics 2006.

21. Wang LY, Zhong Y, Wheeler L. Direct and indirect costs of asthma in school-age children. Prev Chronic Dis 2005: 2: 1-10.

22. Beyhun NE, Soyer ÖU, Kuyucu S, et al. A multi-center survey of childhood asthma in Turkey - I: The cost and its determinants. Pediatr Allergy Immunol 2009: 20: 72-80.

23. Herjavecz I, Nagy GB, Gyurkovits K, et al. Cost, morbidity, and control of asthma in Hungary: The Hunair Study. J Asthma 2003: 40: 673-81.

24. Ferreira-Magalhães M, Sá-Sousa A, Morais-Almeida M, et al. High prevalence of hospitalisation for asthma in a population-based paediatric sample. Arch Dis Child 2015: 100:507-508.

25. Noyes K, Bajorska A, Fisher S, et al. Cost-effectiveness of the school-based asthma therapy (SBAT) program. Pediatrics 2013: 131: e709-e717

26. Karnick P, Margellos-Anast H, Seals G, et al. The pediatric asthma intervention: a comprehensive cost-effective approach to asthma management in a disavantaged inner-city community. J Asthma 2007: 44: 39-44.

27. Briggs AH, Gray AM. Handling uncertainty in economic evaluations of healthcare interventions. BMJ 1999: 319: 635-638.

28. Husereau D, Drummond M, Petrou S, et al. Consolidated health economic evaluation reporting standards (CHEERS)-explanation and elaboration: A report of the ISPOR health economic evaluation publication guidelines good reporting practices task force. Value Heal 2013: 16: 231-250.

This article is protected by copyright. All rights reserved. 
29. Brookman A, Davies G. A Validation of the Health and Social Costs of Asthma Using Questionnaire Data. IJPDS 2017: 1: 164.

Legends

Table 1 Annualised costs (in euros) of childhood asthma in Portugal: total costs, mean cost per child with current asthma and percentage of total costs for each domain/variable.

Table 2 Factors associated with annualised total costs of childhood asthma in Portugal.

Table 3 Multivariate deterministic sensitivity analysis - Annualised total costs extrapolated to total Portuguese children with current asthma and mean costs per patient.

Fig. 1 Mean annual costs per child with current asthma: Total mean annual costs and intervals according to the level of asthma control. Mean costs are marked in euros and the lines represent $95 \%$ CI. $*$ p $<0.001$ between groups of asthma control.

Fig. 2 Mean cost per child with current asthma, per year, in each domain. Panel A: total costs. Panel B: cost variation according to the level of asthma control. ${ }^{*} \mathrm{p}<0.001$ between groups of asthma control.

Table 1

\begin{tabular}{|c|c|c|c|}
\hline & $\begin{array}{c}\text { Total costs in Portuguese } \\
\text { children* } \\
\left(95 \% \mathrm{CI}^{\#}\right)\end{array}$ & $\begin{array}{c}\text { Mean cost per } \\
\text { patient }^{\dagger} \\
\left(95 \% \mathrm{CI}^{\#}\right)\end{array}$ & $\begin{array}{l}\text { Percentage of } \\
\text { total costs }\end{array}$ \\
\hline TOTAL COSTS & $\begin{array}{c}\mathbf{1 6 1}, \mathbf{4 1 0 , 0 0 7 . 6 1} \\
(142,367,218.84-181,369,857.87)\end{array}$ & $\begin{array}{c}929.35 \\
(819.71-1,044.27)\end{array}$ & $100 \%$ \\
\hline DIRECT COSTS & $\begin{array}{c}\mathbf{1 2 1}, \mathbf{3 4 1}, \mathbf{4 9 8 . 0 2} \\
(104,319,912.15-139,851,241.14)\end{array}$ & $\begin{array}{c}\mathbf{6 9 8 . 6 5} \\
(600.64-805.22)\end{array}$ & $75.2 \%$ \\
\hline Healthcare services use & $\begin{array}{c}\mathbf{8 2 , 5 1 9 , 6 8 4 . 1 0} \\
(67,027,110.46-99,248,305.38)\end{array}$ & $\begin{array}{c}\mathbf{4 7 5 . 1 2} \\
(385.92-571.46)\end{array}$ & $51.1 \%$ \\
\hline Scheduled medical visits & $\begin{array}{c}33,414,070.10 \\
(29,192,806.15-38,204,470.63)\end{array}$ & $\begin{array}{c}192.39 \\
(168.08-219.97)\end{array}$ & $20.7 \%$ \\
\hline Acute asthma care & $\begin{array}{c}49,105,614.06 \\
(35,070,014.88-64,089,678.45)\end{array}$ & $\begin{array}{c}282.73 \\
(201.92-369.01)\end{array}$ & $30.4 \%$ \\
\hline Non-scheduled medical visits & $12,766,203.20$ & 73.50 & $7.9 \%$ \\
\hline
\end{tabular}

This article is protected by copyright. All rights reserved. 


\begin{tabular}{|c|c|c|c|}
\hline & $(9,809,363.94-15,874,252.35)$ & $(56.48-91.40)$ & \\
\hline \multirow[t]{2}{*}{ Emergency department visits } & $18,932,464.80$ & 109.01 & $11.7 \%$ \\
\hline & $(13,136,536.12-26,300,288.04)$ & $(75.64-151.43)$ & \\
\hline \multirow[t]{2}{*}{ Hospitalisation } & $17,406,946.00$ & 100.22 & $10.8 \%$ \\
\hline & $(6,189,712.95-30,072,795.68)$ & $(35.64-173.15)$ & \\
\hline \multirow[t]{2}{*}{ Diagnostic tests } & $9,128,914.10$ & 52.56 & $5.7 \%$ \\
\hline & $(7,988,735.48-10,293,812.35)$ & $(46.00-59.27)$ & \\
\hline \multirow[t]{2}{*}{ Blood workout } & $2,498,121.71$ & 14.38 & $1.5 \%$ \\
\hline & $(2,056,174.62-3,027,259.83)$ & $(11.84-17.43)$ & \\
\hline \multirow[t]{2}{*}{ Chest x-ray } & $867,148.15$ & 4.99 & $0.5 \%$ \\
\hline & $(726,594.46-1,012,508.13)$ & $(4.18-5.83)$ & \\
\hline \multirow[t]{2}{*}{ Pulmonary function tests } & $4,840,864.14$ & 27.87 & $3.0 \%$ \\
\hline & $(4,047,079.93-5,594,160.80)$ & $(23.30-32.21)$ & \\
\hline \multirow[t]{2}{*}{ Skin prick tests } & $922,780.11$ & 5.31 & $0.6 \%$ \\
\hline & $(787,921.22-1,060,409.35)$ & $(4.54-6.11)$ & \\
\hline \multirow[t]{2}{*}{ Treatment } & $29,692,899.78$ & 170.96 & $18.4 \%$ \\
\hline & $(26,638,427.58-32,734,734.89)$ & $(153.38-188.48)$ & \\
\hline \multirow[t]{2}{*}{ Asthma-specific medication } & $16,005,602.20$ & 92.16 & $9.9 \%$ \\
\hline & $(14,170,511.21-16,552,789.28)$ & $(81.59-102.71)$ & \\
\hline \multirow[t]{2}{*}{ Controller medication } & $14,731,639.10$ & 84.82 & $9.1 \%$ \\
\hline & $(12,945,695.43-16,516,489.95)$ & $(74.54-95.31)$ & \\
\hline \multirow[t]{2}{*}{ Reliever medication } & $1,273,963.08$ & 7.34 & $0.8 \%$ \\
\hline & $(1,122,865.03-1,433,510.87)$ & $(6.47-8.25)$ & \\
\hline \multirow[t]{2}{*}{ Other asthma medication } & $10,789,280.82$ & 62.12 & $6.7 \%$ \\
\hline & $(8,948,166.70$ - 12,786,638.37) & $(51.52-73.62)$ & \\
\hline \multirow[t]{2}{*}{ Immunotherapy } & $7,403,386.43$ & 42,63 & $4.6 \%$ \\
\hline & $(5,663,424.78-9,313,209.42)$ & $(32.61-53.62)$ & \\
\hline \multirow[t]{2}{*}{ Antihistamines } & $1,792,454.72$ & 10.32 & $1.1 \%$ \\
\hline & $(1,663,308.20-1,910,421.53)$ & $(9.58-11.00)$ & \\
\hline \multirow[t]{2}{*}{ Antibiotics } & $1,491,836.29$ & 8.59 & $0.9 \%$ \\
\hline & $(1,264,692.94-1,736,306.33)$ & $(7.28-10.00)$ & \\
\hline \multirow[t]{2}{*}{ Flu vaccine } & $101,603.39$ & 0.59 & $0.1 \%$ \\
\hline & (n.a.) & (n.a.) & \\
\hline Holding chamber & $2,898,016.76$ & 16.69 & $1.8 \%$ \\
\hline
\end{tabular}

This article is protected by copyright. All rights reserved. 


\begin{tabular}{|c|c|c|c|}
\hline INDIRECT COSTS & $\begin{array}{c}\mathbf{4 0 , 0 6 8 , 5 0 9 . 5 9}(34,117,635.12 \\
-46,811,024.16)\end{array}$ & $\begin{array}{c}\mathbf{2 3 0 . 7 0} \\
(196.44-269.52)\end{array}$ & $24.8 \%$ \\
\hline \multirow[t]{2}{*}{ Parental absenteeism } & $13,689,797.60$ & 78.82 & $8.5 \%$ \\
\hline & $(10,775,047.66-16,906,907.47)$ & $(62.04-97.34)$ & \\
\hline \multirow[t]{2}{*}{ Transportation } & $3,931,536.64$ & 22.64 & $2.4 \%$ \\
\hline & $(3,397,478.25-4,553,290.57)$ & $(19.56-26.22)$ & \\
\hline \multirow[t]{2}{*}{ Subsidies } & $22,447.175 .39$ & 129.24 & $13.9 \%$ \\
\hline & $(17,551,402.93-27,735,327.31)$ & $(101.06-159.69)$ & \\
\hline
\end{tabular}

Each cost item was calculated for each participant by multiplying the parent/self-reported amount of resources used by the unitary costs of the resources. Costs were indexed to 2010 Portuguese prices in euros.

*Total costs were extrapolated to total Portuguese children with current asthma $(n=173,681)(9)$; ${ }^{*}$ Bootstrapped 95\% confidence interval; n.a, not applicable ${ }^{\dagger}$ Mean cost per patient: sum of the total cost of each participant, dividing for the total number of asthmatic children in our sample.

\section{Table 2}

\begin{tabular}{|c|c|c|c|}
\hline & \multirow{2}{*}{ Mean cost (SD) } & \multicolumn{2}{|c|}{$\begin{array}{l}\text { Factors associated with childhood } \\
\text { asthma costs }\end{array}$} \\
\hline & & $\begin{array}{l}\text { Crude association } \\
\qquad(95 \% \mathrm{CI})\end{array}$ & $\begin{array}{l}\text { Adjusted association* } \\
(95 \% \mathrm{CI})\end{array}$ \\
\hline \multicolumn{4}{|l|}{ Gender } \\
\hline Female & $999.44(1,155.01)$ & (ref) & n.i. \\
\hline Male & $888.99 \quad(806.34)$ & $0.89(0.67-1.18)$ & n.i. \\
\hline \multicolumn{4}{|l|}{ Age groups } \\
\hline $0-5$ years old & $1,035.91(1,146.11)$ & (ref) & (ref) \\
\hline $6-12$ years old & $969.84 \quad(974.54)$ & $0.94(0.60-1.46)$ & $0.86(0.59-1.26)$ \\
\hline 13-17 years old & $681.33 \quad(618.04)$ & $0.66(0.39-1.14)$ & $0.64(0.40-1.03)$ \\
\hline \multicolumn{4}{|l|}{ Caregiver education } \\
\hline No education & $1,190.65(1,311.41)$ & (ref) & n.i. \\
\hline $0-4$ years (basic $1^{\text {st }}$ cycle) & $1,011.55(1,151.59)$ & $0.85(0.49-1.47)$ & n.i. \\
\hline 5-9 years (basic $2^{\text {nd }}$ and $3^{\text {rd }}$ cycle) & $1,010.83(1,136.31)$ & $0.85(0.51-1.42)$ & n.i. \\
\hline 10-12 years (secondary) & $669.32 \quad(442.65)$ & $0.56(0.32-1.01)$ & n.i. \\
\hline >12 years (higher) & $840.07 \quad(477.72)$ & $0.71(0.41-1.21)$ & n.i. \\
\hline \multicolumn{4}{|l|}{ Mensal income of caregiver } \\
\hline$<650.00 €$ & $1,064.76(1,187.16)$ & (ref) & n.i. \\
\hline $650.00-749.99 €$ & $1,009.69 \quad(909.77)$ & $0.95(0.67-1.35)$ & n.i. \\
\hline
\end{tabular}

This article is protected by copyright. All rights reserved. 


$\begin{array}{lrrrr}750.00-1,199.99 € & 839.60 & (972.68) & 0.79(0.52-1.21) & \text { n.i. } \\ >=1,200.00 € & 755.10 & (550.96) & 0.71(0.50-1.02) & \text { n.i. }\end{array}$

\section{Wheezing}

$\begin{array}{llllll}\text { No } & 776.19 & (746.83) & 1.00 & \text { (ref) } & \text { n.i. } \\ \text { Yes } & 964.25 & (985.50) & 1.24 & (0.84-1.83) & \text { n.i. }\end{array}$

Nocturnal symptoms

$\begin{array}{lrrrrr}\text { No } & 685.41 & (588.66) & 1.00 & \text { (ref) } & \text { n.i. } \\ \text { Yes } & 1,014.00 & (1,034.80) & \mathbf{1 . 4 8} & (\mathbf{1 . 0 7 - 2 . 0 5}) & \text { n.i. }\end{array}$

Asthma attacks

$\begin{array}{lrrrrrr}\text { No } & 677.58 & (713.02) & 1.00 & \text { (ref) } & 1.00 & \text { (ref) } \\ \text { Yes } & 1,136.82 & (1,058.60) & \mathbf{1 . 6 8} & (\mathbf{1 . 2 7 - 2 . 2 2}) & \mathbf{1 . 5 7} & (\mathbf{1 . 2 2}-\mathbf{2 . 0 2})\end{array}$

Asthma control

\begin{tabular}{|c|c|c|c|}
\hline Controlled & (562.79) & (ref) & (ref) \\
\hline Partly controlled & $1,120.50(1,135.96)$ & $1.50(1.14-1.98)$ & $1.46(1.12-1.90)$ \\
\hline Uncontrolled & $1,758.44(1,795.65)$ & $2.35(1.60-3.47)$ & $2.25(1.56-3.24)$ \\
\hline
\end{tabular}

SD: standard deviation. 95\%CI: 95\% confidence interval.

Bold values show statistical significant differences. n.i.: not included in the model (non-significant variables)

*Adjusted coefficients were calculated using multivariate mixed Poisson-gamma (Tweedie distribution family) generalised linear models. Goodness-of-fit statistics for the multivariate regression model: scaled deviance ( $\mathrm{D}=2,919.3 ; \mathrm{df}=181)$; scaled Pearson chisquare $(\mathrm{v} 2=181.0 ; \mathrm{df}=181) ; \mathrm{AIC}=5,111.3$; consistent $\mathrm{AIC}=5,136.7$

Table 3

\begin{tabular}{lccc}
\hline & $\begin{array}{c}\text { Costs in Portuguese } \\
\text { childhood asthma }\end{array}$ & \multicolumn{2}{c}{ Multivariate sensitivity analysis } \\
\cline { 3 - 4 } & & Best-case scenario* & Worst-case scenario" $^{*}$ \\
\hline \hline TOTAL COSTS & $\mathbf{1 6 1 , 4 1 0 , 0 0 7 . 6 1}$ & $\mathbf{7 9 , 5 8 5 , 9 6 0 . 0 0}$ & $\mathbf{3 0 8 , 0 1 8 , 9 5 2 . 5 5}$ \\
& $\mathbf{( 9 2 9 . 3 5 )}$ & $\mathbf{( 6 0 6 . 9 9 )}$ & $\mathbf{( 1 , 4 2 4 . 3 8 )}$ \\
\hline DIRECT COSTS & $\mathbf{1 2 1 , 3 4 1 , 4 9 8 . 0 2}$ & $\mathbf{5 8 , 5 3 5 , 0 4 7 . 1 3}$ & $\mathbf{2 4 6 , 5 3 8 , 0 5 2 . 4 9}$ \\
Healthcare services use & $\mathbf{( 6 9 8 . 6 5 )}$ & $\mathbf{( 4 4 6 . 4 4 )}$ & $\mathbf{( 1 , 1 4 0 . 0 7 )}$ \\
& $\mathbf{8 2 , 5 1 9 , 6 8 4 . 1 0}$ & $\mathbf{4 2 , 5 9 5 , 5 7 1 . 3 5}$ & $\mathbf{1 3 8 , 3 2 9 , 9 3 6 . 9 9}$ \\
Scheduled medical visits & $\mathbf{( 4 7 5 . 1 2 )}$ & $\mathbf{( 3 2 4 . 8 7 )}$ & $\mathbf{( 6 3 9 . 6 8 )}$ \\
& $33,414,070.10$ & $23,171,710.16$ & $44,989,758.82$ \\
Acute asthma care & $(192.39)$ & $(176.73)$ & $(208.05)$ \\
& $49,105,614.00$ & $19,423,861.19$ & $93,340,178.17$ \\
& $(282.73)$ & $(148.14)$ & $(431.63)$
\end{tabular}

This article is protected by copyright. All rights reserved. 


\begin{tabular}{|c|c|c|c|}
\hline \multirow[t]{2}{*}{ Emergency department visits } & $18,932,464.80$ & $10,627,732.56$ & $29,012,394.70$ \\
\hline & $(109.01)$ & $(81.06)$ & $(134.16)$ \\
\hline \multirow[t]{2}{*}{ Hospitalisation } & $17,406,946.00$ & $2,628,165.12$ & $43,346,333.38$ \\
\hline & $(100.22)$ & $(20.04)$ & $(200.45)$ \\
\hline \multirow[t]{2}{*}{ Diagnostic tests } & $9,128,914.10$ & $5,000,033.78$ & $14,486,032.35$ \\
\hline & (52.56) & (38.13) & $(66.99)$ \\
\hline \multirow[t]{2}{*}{ Blood workout } & $2,498,121.71$ & $1,305,608.05$ & $4,067,419.36$ \\
\hline & (14.38) & $(9.96)$ & (18.81) \\
\hline \multirow[t]{2}{*}{ Chest x-ray } & $867,148.15$ & $458,238.33$ & $1,403,577.64$ \\
\hline & $(4.99)$ & $(3.49)$ & $(6.49)$ \\
\hline \multirow[t]{2}{*}{ Pulmonary function tests } & $4,840,864.14$ & $2,626,641.61$ & $7,722,475.88$ \\
\hline & $(27.87)$ & $(20.03)$ & $(35.71)$ \\
\hline \multirow[t]{2}{*}{ Skin prick tests } & $922,780.11$ & $609,545.80$ & $1,292,559.47$ \\
\hline & $(5.31)$ & $(4.65)$ & $(5.98)$ \\
\hline \multirow[t]{2}{*}{ Treatment } & $29,692,899.78$ & $10,939,442.00$ & $93,722,083.15$ \\
\hline & $(170.96)$ & $(83.43)$ & $(433.40)$ \\
\hline \multirow[t]{2}{*}{ Asthma-specific medication } & $16,005,602.20$ & $3,225,956.01$ & $67,162,295.84$ \\
\hline & $(92.16)$ & $(24.60)$ & $(310.58)$ \\
\hline \multirow[t]{2}{*}{ Controller medication } & $14,731,639.10$ & $2,883,526.64$ & $63,387,483.49$ \\
\hline & $(84.82)$ & (21.99) & (293.12) \\
\hline \multirow[t]{2}{*}{ Reliever medication } & $1,273,963.08$ & $342,429.37$ & $3,774,812.35$ \\
\hline & $(7.34)$ & $(2.61)$ & $(17.46)$ \\
\hline \multirow[t]{2}{*}{ Other asthma medication } & $10,789,280.82$ & $5,819,598.60$ & $22,412,953.76$ \\
\hline & $(62.12)$ & $(44.39)$ & $(103.64)$ \\
\hline \multirow[t]{2}{*}{ Immunotherapy } & $7,403,386.43$ & $4,017,060.24$ & $16,754,942.43$ \\
\hline & $(42.63)$ & $(30.64)$ & $(77.48)$ \\
\hline \multirow[t]{2}{*}{ Antihistamines } & $1,792,454.72$ & $1,127,631.03$ & $2,603,722.95$ \\
\hline & $(10.32)$ & $(8.60)$ & $(12.04)$ \\
\hline \multirow{2}{*}{ Antibiotics } & $1,491,836.29$ & $636,556.20$ & $2,826,579.23$ \\
\hline & $(8.59)$ & $(4.85)$ & (13.07) \\
\hline \multirow[t]{2}{*}{ Flu vaccine } & $101,603.39$ & $38,351.14$ & $227,709.14$ \\
\hline & $(0.59)$ & $(0.29)$ & $(1.05)$ \\
\hline Holding chamber & $2,898,016.76$ & $1,893,887.38$ & $4,146,833.55$ \\
\hline
\end{tabular}

This article is protected by copyright. All rights reserved. 


\begin{tabular}{lccc}
\hline INDIRECT COSTS & $\mathbf{4 0 , 0 6 8 , 5 0 9 . 5 9}$ & $\mathbf{2 1 , 0 5 0 , 9 1 2 . 8 8}$ & $\mathbf{6 1 , 4 8 0 , 9 0 0 . 0 6}$ \\
Parental absenteeism & $\mathbf{( 2 3 0 . 7 0 )}$ & $\mathbf{( 1 6 0 . 5 5 )}$ & $\mathbf{( 2 8 4 . 3 1 )}$ \\
& $13,689,797.60$ & $8,312,678.55$ & $20,379,882.34$ \\
Transportation & $(78.82)$ & $(63.40)$ & $(94.24)$ \\
& $3,931,536.64$ & $2,770,123.76$ & $5,221,446.58$ \\
Subsidies & $(22.64)$ & $(21.13)$ & $(24.15)$ \\
& $22,447,175.39$ & $9,968,110.57$ & $41,101,017.72$ \\
& $(129.24)$ & $(76.03)$ & $(190.06)$
\end{tabular}

*Best-case scenario was set with: the lower limit of the 95\%CI of current asthma prevalence in Portuguese children; scenario of minimum use of asthma medications; and the lower limit of the $95 \% \mathrm{CI}$ for the proportion of occurrence of each variable in Portuguese population. \#Worst-case scenario was set with: the upper limit of the $95 \% \mathrm{CI}$ of current asthma prevalence in Portuguese children; scenario of maximum use of asthma medications; and the upper limit of the $95 \% \mathrm{CI}$ for the proportion of occurrence of each variable in Portuguese population.

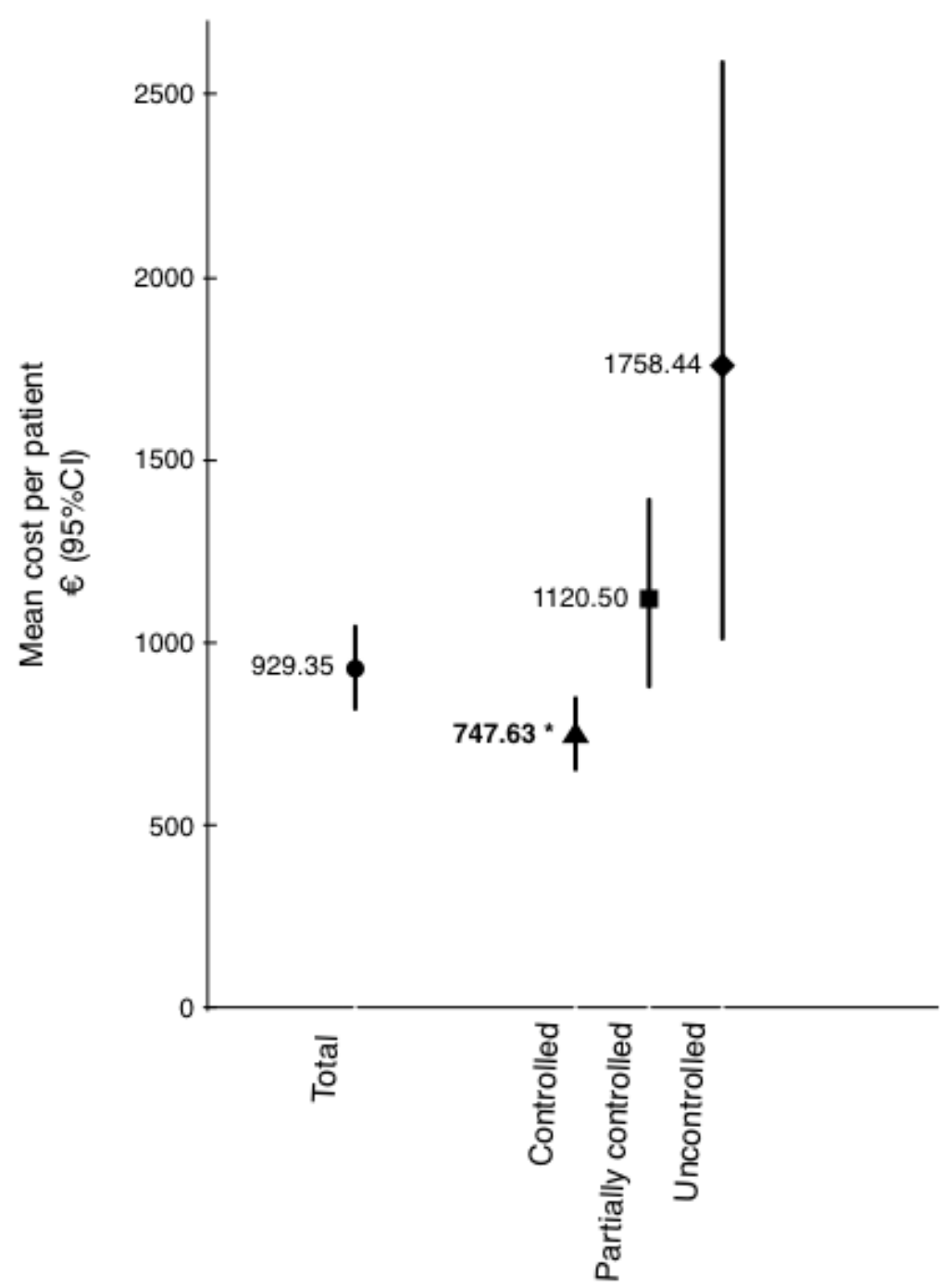

This article is protected by copyright. All rights reserved. 


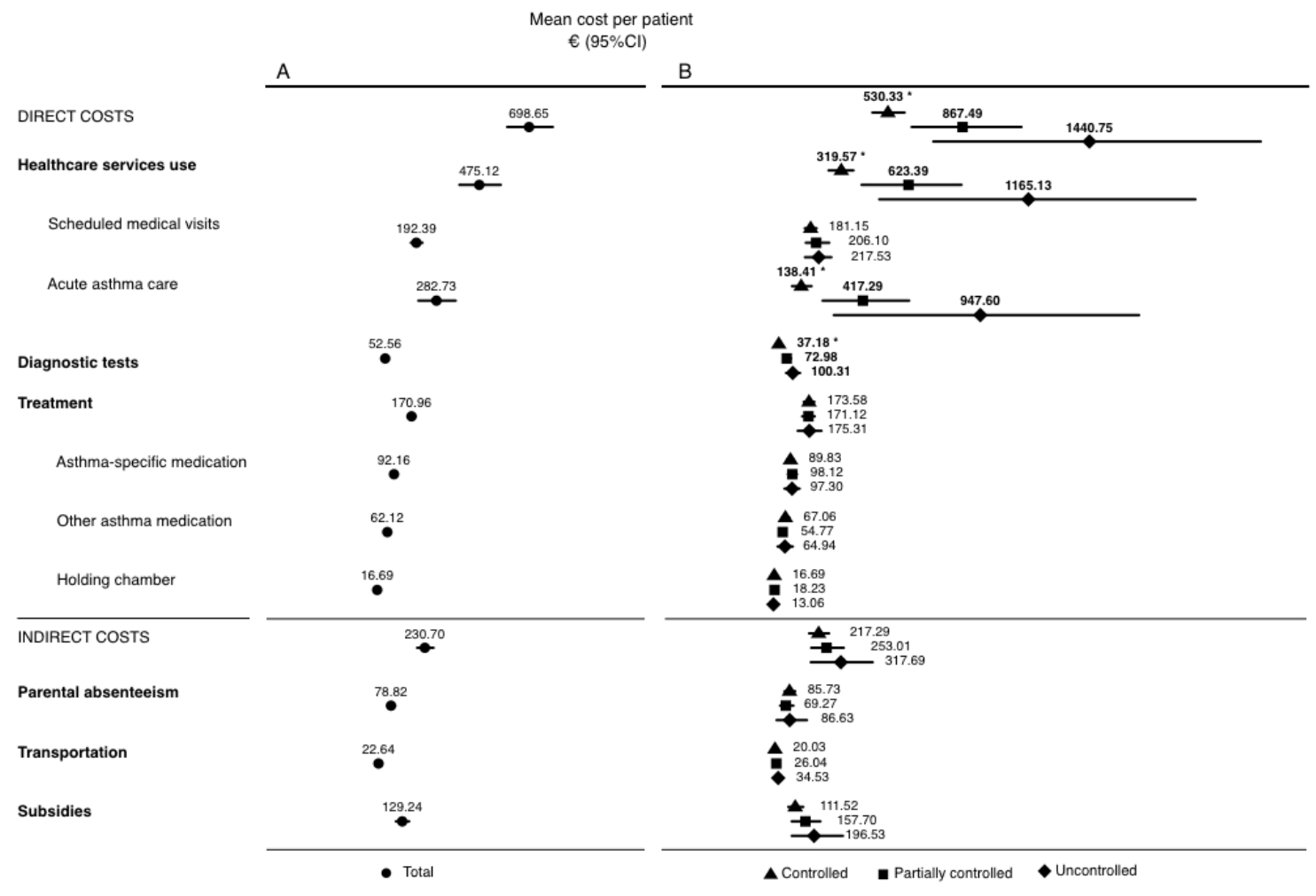

This article is protected by copyright. All rights reserved. 